\title{
Effects of Pleurotus eryngii polysaccharides on bacterial growth, texture properties, proteolytic capacity, and angiotensin-I-converting enzyme-inhibitory activities of fermented milk
}

\author{
Siqian Li and Nagendra P. Shah ${ }^{1}$ \\ Food and Nutritional Sciences, School of Biological Sciences, University of Hong Kong, Pokfulam Road, Hong Kong
}

\begin{abstract}
Pleurotus eryngii is one of the most favored oyster mushrooms and contains various beneficial bioactive compounds. Polysaccharide extracted from P. eryngii (PEPS) was added as a natural-source ingredient to milk before fermentation, and the effects of additional PEPS on fermented milk were investigated in this study. The PEPS were extracted and added to reconstituted skim milk $(12 \%, \mathrm{wt} / \mathrm{vol})$ at $0.5,0.25$, and $0.125 \%$ (wt/vol) and fermented by a non-exopolysaccharide-producing strain, Streptococcus thermophilus Australian Starter Culture Collection (ASCC) 1303 (ST 1303), or an exopolysaccharide-producing Strep. thermophilus ASCC 1275 (ST 1275). Bacterial growth, texture properties, microstructure, proteolytic capacity, and angiotensinI-converting enzyme-inhibitory activities of fermented milk (FM) were determined during refrigerated storage at $4^{\circ} \mathrm{C}$ for $21 \mathrm{~d}$. Viable counts of starter bacteria in FM with $0.5 \%$ PEPS added were the highest. Changes in $\mathrm{pH}$ were consistent with changes in titratable acidities for all samples. The FM samples with added PEPS showed denser protein aggregates containing larger serum pores in confocal micrographs compared with those without PEPS at $\mathrm{d} 0$ and 21 during refrigerated storage. The values for spontaneous whey separation of FM with added PEPS were significantly higher than those of FM fermented by ST 1303 or ST 1275 without PEPS. The proteolytic activities of ST 1303 of FM with added PEPS were higher than those of FM fermented by ST 1303 without PEPS. The FM with added $0.125 \%$ PEPS had similar angiotensin-I-converting enzyme-inhibitory activity to that fermented by ST 1303 without PEPS; both were higher than those of other samples during refrigerated storage. Firmness and gumminess values of FM with added PEPS were higher than those of FM fermented by ST 1303 or ST 1275 without PEPS.
\end{abstract}

Received November 16, 2014.

Accepted January 23, 2015.

${ }^{1}$ Corresponding author: npshah@hku.hk
Key words: Pleurotus eryngii, polysaccharide, probiotic, prebiotic, fermented milk

\section{INTRODUCTION}

Yogurt is a classic example of a functional food, the consumption of which has increased significantly over the past few years. Traditional yogurt is the fermentation product of milk with a mix of lactic acid bacteria (LAB) such as Lactobacillus delbrueckii ssp. bulgaricus and Streptococcus thermophilus. These are gram-positive organisms that produce lactic acid as the major end product during fermentation (Shah, 2007). Current industrial practice in Australia could use Strep. thermophilus alone to make yogurts, because it results in a mild flavor of final products (Purwandari et al., 2007). In addition to the health benefits of consuming LAB from yogurt, these LAB also produce various secondary metabolites that have been associated with health benefits (Shah, 2007; Ramchandran and Shah, 2010a,b). Lactic acid bacteria play an important role in the textural development of yogurts and other fermented dairy products (Zisu and Shah, 2003). Exopolysaccharides (EPS) are produced by some LAB during fermentation. The texture of fermented-milk (FM) products often depends on the EPS, which is essential for proper consistency and texture of products (Hassan et al., 1996; Zisu and Shah, 2003). Several studies showed that EPS affect textural and physical properties of FM products and improve sensory characteristics such as mouthfeel, ropiness, and creaminess (Ramchandran and Shah, 2009; Yang et al., 2014). The microstructures of FM products were classified into homogeneous and phase separated, which could be investigated by confocal laser scanning microscopy (CLSM) at length scales above 1 $\mu \mathrm{m}$ (van den Berg et al., 2007).

Mushrooms contain various bioactive compounds and have been used as food and medicine by humans for centuries. Pleurotus eryngii, a type of edible mushroom, contains various beneficial bioactive compounds such as polyphenols, polysaccharides, peptides, and dietary fibers (Ferreira et al., 2009). It is reported to be 
a good dietary source for prevention of hyperlipidemic, hepatogenic, atherosclerotic conditions and tumors (Bobek and Galbavy, 2001; Ping et al., 2009; Chen et al., 2012). Demand is growing in the food industry for new functional ingredients or bioactive components from natural sources because they are widely applied to make functional foods, which are anticipated to protect against a wide range of diseases. This has led to an increasing interest in extracting ingredients from food such as mushrooms and developing functional foods (Miao et al., 2011). Several studies have been carried out on the effects of EPS on the textural characteristics of FM products (Folkenberg et al., 2006; Ramchandran and Shah, 2009, 2010a, b). However, very few studies have focused on the influence of mushroom polysaccharides on the texture properties of FM during refrigerated storage, especially polysaccharides from $P$. eryngii. Additionally, very few studies report on the effects of addition of $P$. eryngii polysaccharides in milk on the bacterial growth, microstructure, proteolytic capacity, and angiotensin-I-converting enzyme (ACE)-inhibitory activity of FM during refrigerated storage.

In this study, polysaccharides were extracted from P. eryngii (PEPS), and varying levels of freeze-dried PEPS $(0.125,0.25,0.5 \%$, wt $/ \mathrm{vol})$ were added to reconstituted skim milk (RSM; 12\%, wt/vol) and fermented by non-EPS-producing Strep. thermophilus Australian Starter Culture Collection (ASCC) 1303 (ST 1303). The aims of this work were to compare the influence of additional PEPS on changes in viability of ST 1303, $\mathrm{pH}$ and titratable acid, microstructural changes, proteolytic and ACE-inhibitory activities, firmness and gumminess, and spontaneous whey separation (SWS) of FM during refrigerated storage. These parameters were compared with FM samples fermented by the EPS-producing strain Strep. thermophilus ASCC 1275 (ST 1275) without additional PEPS.

\section{MATERIALS AND METHODS}

\section{Chemicals and Reagents}

Angiotensin-I-converting enzyme from rabbit lung, boric acid, BSA, Coomassie brilliant blue G-250, Dglucose, dinitrosalicylic acid, Folin-Ciocalteu reagent, gallic acid, hippuryl-His-Leu acetate salt, 2-mercaptoethanol, o-phthaldialdehyde, phenol, phenolphthalein, phosphoric acid, SDS, sodium tetraborate decahydrate, and trichloroacetic acid were purchased from Sigma Chemical Co. (St. Louis, MO). Ethanol, ethyl acetate, hydrochloric acid, methanol, sodium chloride, sodium hydroxide, sodium sulfite, and sulfuric acid were purchased from Merck (Darmstadt, Germany).
The M17 broth was purchased from Becton Dickinson and Company (Franklin Lakes, NJ). Nestle (Cabuyao, Laguna, Philippines) Carnation skim milk powder was purchased from the local market.

\section{Activation of Starter Cultures}

The ST 1275 and ST 1303 were originally obtained from the Starter Culture Collection of Dairy Innovation Australia Ltd. (ASCC, Werribee, Victoria, Australia). The ST 1275 was used as an EPS-producing strain and ST 1303 as a non-EPS-producing strain in this study (Zisu and Shah, 2003). Sterilized M17 broth (M17 broth is superior to other comparable culture media to cultivate Streptococcus species) was used to grow ST 1275 and ST 1303. Working cultures were propagated 3 times using a $2 \%$ (vol/vol) inoculum in M17 broth at $37^{\circ} \mathrm{C}$ for $24 \mathrm{~h}$ before use.

\section{PEPS and Determination of Composition}

Extraction of polysaccharides from P. eryngii was according to the method of Li and Shah (2014). Briefly, freeze-dried powder of $P$. eryngii was mixed in $95 \%$ ethanol (sample/ethanol, wt/vol, 1:30), and impurities and small lipophilic molecules were removed by keeping the mixture for $24 \mathrm{~h}$ at $25^{\circ} \mathrm{C}$. Polysaccharides were extracted by keeping the sample in hot water at $95.0^{\circ} \mathrm{C}$ for $3 \mathrm{~h}$ (sample/water, wt/vol, 1:30) followed by centrifugation at $3,350 \times g$ (Hitachi high-speed refrigerated centrifuge, model GR22G, Hitachi Ltd., Tokyo, Japan) for $10 \mathrm{~min}$ at room temperature $\left(23^{\circ} \mathrm{C}\right)$. Then the supernatant was precipitated by addition of a $3 \times$ volume of $80 \%$ precooled ethanol at $4^{\circ} \mathrm{C}$ for 24 h. The precipitate as polysaccharides was separated and washed with anhydrous ethanol and lyophilized to obtain PEPS. The total carbohydrate, protein, and total phenolic contents of PEPS were determined by phenol-sulfuric acid method using D-glucose as a reference (Dubois et al., 1956), Bradford method using BSA as a reference, and Folin-Ciocalteu method using gallic acid as a reference, respectively. The reducing sugar was determined following the method reported by Miller (1959) with D-glucose as a reference. Total polysaccharide was considered as the subtraction of reducing sugar from the total carbohydrate. Total phenolic content was expressed as microgram of gallic acid equivalents per gram of dry-weight PEPS.

\section{Preparation of FM}

Five batches of FM samples were made using $12 \%$ (wt/vol) RSM prepared as follows: RSM fermented by 
ST 1275 (FM-ST 1275), RSM fermented by ST 1303 (FM-ST 1303), and RSM with $0.125,0.25$, and $0.5 \%$ (wt/vol) PEPS added and fermented by ST 1303 (FMST $1303+0.125 \%$ PEPS, FM-ST $1303+0.25 \%$

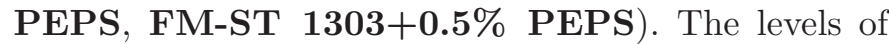
PEPS applied in RSM for making FM samples are as per Miao et al. (2011). Before inoculation, ST 1275 and ST 1303 were activated by growing 3 times consecutively at $37^{\circ} \mathrm{C}$ for $24 \mathrm{~h}$ in sterile RSM followed by the fourth transfer into sterile RSM before making FM using an inoculum level of $2 \%$ (vol/vol). The FM samples were made following the method of Prasad et al. (2013) with some modifications. Briefly, water was preheated to $60^{\circ} \mathrm{C}$, and then the RSM powder and PEPS were added. The heating was then continued to a temperature of $85^{\circ} \mathrm{C}$, and the heated mix was held at this temperature for $30 \mathrm{~min}$ followed by cooling to $37^{\circ} \mathrm{C}$. This was followed by inoculation with ST 1275 or ST 1303 . The inoculated mix was then mixed thoroughly and dispensed in $50-\mathrm{mL}$ tubes with lids and incubated at $37^{\circ} \mathrm{C}$ until the $\mathrm{pH}$ dropped to $4.5 \pm 0.1$. The fermentation was stopped by transferring the tubes immediately to a refrigerator maintained at $4 \pm 1^{\circ} \mathrm{C}$. The FM-making experiment was carried out in triplicate.

\section{Enumeration of Bacteria}

For the enumeration of ST 1275 and ST 1303, a 1-mL aliquot of FM was taken at d $0,7,14$, and 21, and serial dilutions were carried out in sterile $0.85 \%$ saline. Subsequent serial dilutions were vortexed for $30 \mathrm{~s}$ individually before pouring $50-\mu \mathrm{L}$ aliquots into M17 agar plates. Plates were incubated at $37^{\circ} \mathrm{C}$ for $24 \mathrm{~h}$ in an anaerobic jar. Plates showing 25 to 250 colonies were counted, and results were expressed as colony-forming units (cfu) per milliliter of the inoculated sample.

\section{pH Measurement and Titratable-Acidity Determination}

The change in $\mathrm{pH}$ was measured at $\mathrm{d} 0,7,14$, and 21 using a pH meter (model 250A, Science International Corporation, Hong Kong) after calibrating with fresh $\mathrm{pH} 4.01$ and 7.00 standard buffers. Samples were tempered to room temperature $\left(23^{\circ} \mathrm{C}\right)$ before the $\mathrm{pH}$ measurement. The titratable acidity of FM was determined as per the AOAC titration method (AOAC International, 1999). Briefly, $10.0 \mathrm{~g}$ of FM was diluted with the same weight of Milli-Q water (EMD Millipore, Merck KGaA, Darmstadt, Germany) and titrated using $0.1 \mathrm{M} \mathrm{NaOH}$. The titratable acidity was expressed as percent lactic acid.

\section{CLSM}

The Carl Zeiss LSM710 NLO CLSM with Multiphoton System (Jena, Germany) was used to investigate the structural features of all FM samples. The CLSM was equipped with an inverted microscope, and Zeiss objective lenses (magnification $5 \times, 10 \times$, and $40 \times$ ) were used. Digital image files are acquired in a tagged image file format at 1,024 × 1,024 pixel resolution. For CLSM observation, FM samples were stained with Nile red (1 $\mathrm{mg} / \mathrm{mL}$ in ethanol solution) and fluorescein isothiocyanate (FITC, $1 \mathrm{mg} / \mathrm{mL}$ in ethanol solution) for 30 min. Briefly, $10 \mathrm{~mL}$ of sample was mixed with $100 \mu \mathrm{L}$ of Nile red and $100 \mu \mathrm{L}$ of FITC. Afterward, $100 \mu \mathrm{L}$ of stained sample was pipetted to a glass slide, sealed with a coverslip, and applied to the CLSM immediately. The CLSM observation was carried out in a dark room, and the excitation/emission wavelength of Nile Red and FITC was set at $534 \mathrm{~nm} / 500$ to $600 \mathrm{~nm}$ and $488 \mathrm{~nm} / 495$ to $559 \mathrm{~nm}$, respectively.

\section{sWS}

Spontaneous whey separation, defined as the whey expelled from the gel without the application of external pressure, was determined by the method of Amatayakul et al. (2006) with some modifications. This method represents the actual values of syneresis of the whey separation on the surface of FM that does not cause damages to the structure of the FM products. Briefly, a tub of FM sample was taken out from the refrigerator at $4^{\circ} \mathrm{C}$ and weighed immediately and then kept at an angle of approximately $45^{\circ}$ to collect the surface whey on the side of the tub. The collected whey was siphoned out with a pipette. The siphoning process was performed within $10 \mathrm{~s}$ to avoid forced leakage of whey from the curd, the tub was weighed, and whey separation was expressed as the percent weight of the whey over the initial weight of the FM.

\section{Extent of Proteolysis}

The extent of proteolysis was determined by the o-phthaldialdehyde method according to Church et al. (1983) with some modifications. Briefly, $3 \mathrm{~mL}$ of $o$-phthaldialdehyde reagent was added into $150 \mu \mathrm{L}$ of filtrate and vortexed for $5 \mathrm{~s}$, and the absorbance value was measured at $340 \mathrm{~nm}$ within 2 min using a UV-VIS spectrophotometer (Shimadzu Scientific Instruments, Kyoto, Japan). The readings of the reagent blank were deducted from the corresponding readings of FM samples to obtain the amount of free amino acids released 
as a consequence of the proteolytic capacities of the starter cultures during fermentation and storage.

\section{Determination of ACE-Inhibitory Activity}

The ACE-inhibitory activity was determined according to the method of Cushman and Cheung (1971) with some modifications. Briefly, $200 \mu \mathrm{L}$ of Hip-His-Leu (5 $\mathrm{m} M$ in $0.1 M$ borate buffer) was mixed with $60 \mu \mathrm{L}$ of borate buffer $(0.1 \mathrm{M}$ solution containing $0.3 \mathrm{M} \mathrm{NaCl}$, $\mathrm{pH} 8.30$ ) and $30 \mu \mathrm{L}$ of the filtrate and incubated at $37^{\circ} \mathrm{C}$ for $10 \mathrm{~min}$. Thereafter, $20 \mu \mathrm{L}$ of ACE solution $(0.1$ unit $/ \mathrm{mL}$ ) was added, and the mixture was incubated at $37^{\circ} \mathrm{C}$ for $30 \mathrm{~min}$. The enzyme activity was terminated with $250 \mu \mathrm{L}$ of $1 \mathrm{M} \mathrm{HCl}$. Hippuric acid formed was extracted by mixing in $1.7 \mathrm{~mL}$ of ethyl acetate. After standing for $10 \mathrm{~min}$, the mixture was centrifuged at $5,000 \times g$ for $10 \mathrm{~min}$ at $23^{\circ} \mathrm{C}$, and then $1.2 \mathrm{~mL}$ of the separated solvent layer was siphoned out and dried in a water bath for $1 \mathrm{~h}$ at $100^{\circ} \mathrm{C}$. The dried hippuric acid was dissolved in $1.0 \mathrm{~mL}$ of Milli-Q water, and absorbance was measured at $228 \mathrm{~nm}$ using a UV-VIS spectrophotometer. The ACE-inhibitory activity was calculated using the following formula:

$$
\text { ACE-inhibitory activity }(\%)=\left[1-\frac{C-D}{A-B}\right] \times 100,
$$

where $A$ is the absorbance with ACE and without the sample; $B$ is the absorbance without both ACE and the sample; $C$ is the absorbance with both ACE and the sample; and $D$ is the absorbance without ACE but with the sample. The ACE-inhibitory activity was also expressed in terms of $\mathbf{E C}_{50}$, which is defined as the protein concentration in the sample $(\mathrm{mg} / \mathrm{mL})$ effective to inhibit $50 \%$ of the ACE activity. The protein content of the filtrate was determined by the method of Lowry et al. (1951) using BSA as a reference.

\section{Texture Analysis}

Texture analysis of FM was carried out using a texture analyzer TA.XT2 (Stable Micro System Ltd., Godalming, UK) with a P20 probe (diameter $20 \mathrm{~mm}$ ) and $25-\mathrm{kg}$ load cell. The penetration speed was set at $1 \mathrm{~mm} / \mathrm{s}$, and the penetration depth was set at $10 \mathrm{~mm}$. Texture analysis was performed immediately after the samples were removed from the refrigerator at $4^{\circ} \mathrm{C}$. Firmness of the FM was expressed in grams.

\section{Statistical Analysis}

Data reported are mean $\pm \mathrm{SD}$ of triplicate determinations of each sample. One-way ANOVA and Tukey's tests at $95 \%$ confidence intervals were performed using IBM SPSS Statistics 20.0 (Armonk, NY).

\section{RESULTS AND DISCUSSION}

\section{Composition of PEPS}

For PEPS, the contents of total carbohydrate, total polysaccharides, reducing sugar, total phenolics, and protein content were $796.11 \pm 42.13 \mathrm{mg} / \mathrm{g}, 647.20 \pm$ $29.27 \mathrm{mg} / \mathrm{g}, 148.91 \pm 1.72 \mathrm{mg} / \mathrm{g}, 17.53 \pm 1.73 \mathrm{mg}$ of gallic acid equivalents/g, and $21.58 \pm 0.83 \mathrm{mg} / \mathrm{g}$, respectively.

\section{Enumeration of Bacteria}

Viable count changes of ST 1275 and ST 1303 in log cfu per milliliter observed in FM during 21-d storage at $4^{\circ} \mathrm{C}$ are presented in Table 1 . Viable counts at $\mathrm{d} 0$ were the number of ST 1275 or ST 1303 in FM, which was determined immediately when the $\mathrm{pH}$ values of FM reached $4.5 \pm 0.1$. As shown in the table, the viable counts of ST 1303 or ST 1275 decreased during refrigerated storage. Viable counts of ST 1303 of FMST $1303+0.5 \%$ PEPS were highest as compared with other batches during refrigerated storage. Additionally, viable counts of ST 1303 of FM-ST 1303+0.5\% PEPS and FM-ST $1303+0.25 \%$ PEPS were significantly $(P<$ 0.05) higher than those of FM-ST 1303 at d 0, 7, 14, and 21, which indicated that PEPS was a good growth factor to support the growth of ST 1303 in FM during refrigerated storage. Ramchandran and Shah (2009) reported that high-performance inulin, as a prebiotic, significantly stimulated the growth of ST 1275 in RSM containing $1 \%$ high-performance inulin (high-performance inulin/RSM, wt/vol), which may be because of the production of extracellular enzymes that could hydrolyze long-chain fructans with additional formation of fructose. For other prebiotics such as modified waxy maize starch and galactooligosaccharides, Prasad et al. (2013) reported that $2 \%$ additional galactooligosaccharides or modified waxy maize starch significantly $(P<0.05)$ improved the viability of $L$. delbrueckii ssp. bulgaricus and Strep. thermophilus in nonfat FM during refrigerated storage at $4^{\circ} \mathrm{C}$. Our results showed that PEPS possessed growth properties that were similar to those of inulin, galactooligosaccharides, and modified waxy maize starch. Viable counts of ST 1275 in FM-ST 1275 were significantly $(P<0.05)$ higher than those of ST 1303 in FM-ST 1303 at d 0, 14, and 21, which agrees with previous reports that EPS had a protective effect on the survival of probiotics during refrigerated storage (Amatayakul et al., 2006; Ramchandran and Shah, 2010b). 
Table 1. Changes in viable counts of Streptococcus thermophilus [Australian Starter Culture Collection (ASCC)] 1275 and Strep. thermophilus ASCC 1303 in fermented-milk samples during $21 \mathrm{~d}$ of refrigerated storage at $4^{\circ} \mathrm{C}^{1}$

\begin{tabular}{lcccc}
\hline & \multicolumn{4}{c}{ Period of storage $(\mathrm{d})$} \\
\cline { 2 - 5 } Sample $^{2}$ & 0 & 7 & 14 & 21 \\
\hline FM-ST 1275 & $9.38 \pm 0.10^{\mathrm{A}, \mathrm{ac}}$ & $9.21 \pm 0.17^{\mathrm{AB}, \mathrm{ab}}$ & $9.19 \pm 0.05^{\mathrm{B}, \mathrm{a}}$ & $8.87 \pm 0.17^{\mathrm{C}, \mathrm{a}}$ \\
FM-ST 1303 & $9.19 \pm 0.11^{\mathrm{A}, \mathrm{b}}$ & $9.11 \pm 0.13^{\mathrm{AB}, \mathrm{b}}$ & $9.01 \pm 0.10^{\mathrm{B}, \mathrm{b}}$ & $8.48 \pm 0.11^{\mathrm{C}, \mathrm{b}}$ \\
FM-ST 1303+0.125\% PEPS & $9.35 \pm 0.04^{\mathrm{A}, \mathrm{c}}$ & $9.18 \pm 0.07^{\mathrm{B}, \mathrm{ab}}$ & $8.92 \pm 0.09^{\mathrm{C}, \mathrm{b}}$ & $8.59 \pm 0.11^{\mathrm{D}, \mathrm{b}}$ \\
FM-ST 1303+0.25\% PEPS & $9.47 \pm 0.14^{\mathrm{A}, \mathrm{ac}}$ & $9.33 \pm 0.11^{\mathrm{A}, \mathrm{c}}$ & $9.14 \pm 0.19^{\mathrm{B}, \mathrm{ab}}$ & $8.86 \pm 0.32^{\mathrm{B}, \mathrm{a}}$ \\
FM-ST 1303+0.5\% PEPS & $9.48 \pm 0.05^{\mathrm{A}, \mathrm{a}}$ & $9.44 \pm 0.16^{\mathrm{A}, \mathrm{c}}$ & $9.43 \pm 0.10^{\mathrm{A}, \mathrm{c}}$ & $9.12 \pm 0.20^{\mathrm{B}, \mathrm{c}}$ \\
${ }^{\mathrm{A}-\mathrm{D}}$ Means in the same row without common superscripts are significantly different $(P<0.05)$. \\
${ }^{\mathrm{a}-\mathrm{c} M e a n s}$ in the same column without common superscripts are significantly different $(P<0.05)$. \\
${ }^{1}$ Values are expressed as log cfu/mL (mean \pm SD, n $=3$ ). \\
${ }^{2}$ FM-ST 1275 = milk fermented by Strep. thermophilus ASCC 1275; FM-ST 1303 = milk fermented by Strep. \\
thermophilus ASCC 1303; PEPS = Pleurotus eryngii polysaccharides. The PEPS were added as mass percent.
\end{tabular}

\section{pH Measurement and Titratable-Acidity Determination}

Changes in $\mathrm{pH}$ and titratable acidity of $\mathrm{FM}$ during refrigerated storage are shown in Table 2 . The $\mathrm{pH}$ of FM-ST 1275 decreased during refrigerated storage, and a significant $(P<0.05)$ decrease existed at d $14(4.24 \pm$ $0.03)$ as compared with that of d $7(4.52 \pm 0.05)$. Similarly, the titratable acidity of FM-ST 1275 increased during refrigerated storage, which was consistent with the decrease in $\mathrm{pH}$. The $\mathrm{pH}$ of FM-ST 1303, FM-ST $1303+0.5 \%$ PEPS, and FM-ST $1303+0.25 \%$ PEPS decreased at $\mathrm{d} 7$ and then kept increasing at $\mathrm{d} 14$ and 21. The titratable acidities of FM products were also consistent with the trend in changes in $\mathrm{pH}$ values during refrigerated storage. A similar observation was reported by Ramchandran and Shah (2010b) in low-fat yogurts with added $3 \%$ inulin (wt/vol) that was fermented by
ST 1275. Tinson et al. (1982) indicated that those basic metabolites produced by Strep. thermophilus during later part of storage could be the possible reasons for the increase in $\mathrm{pH}$ observed at d 14 and 21 .

\section{CLSM}

Micrographs of FM samples stored at $4^{\circ} \mathrm{C}$ for $0 \mathrm{~d}(\mathbf{D}$ 0) and $21 \mathrm{~d}$ (D 21) obtained by CLSM are shown in Figure 1. Nile red-stained fat globules appeared red, and FITC-stained homogeneous matrix of protein appeared green. Denser protein aggregates appeared light green or light yellow, and the black areas were serum pores (Cruz et al., 2009; Nguyen et al., 2014). Micrographs of FM-ST 1275 and FM-ST 1303 showed no significant differences between each other, and both samples showed homogeneous structure of the protein matrix and fat globules at d 0 and 21. For FM-ST 1303, pro-

Table 2. Changes in $\mathrm{pH}$ and titratable acidity (\%) of fermented-milk samples during $21 \mathrm{~d}$ of storage at $4^{\circ} \mathrm{C}^{1}$

\begin{tabular}{|c|c|c|c|c|}
\hline \multirow[b]{2}{*}{ Sample $^{2}$} & \multicolumn{4}{|c|}{ Period of storage (d) } \\
\hline & 0 & 7 & 14 & 21 \\
\hline \multicolumn{5}{|l|}{$\mathrm{pH}$} \\
\hline FM-ST 1275 & $4.56 \pm 0.05^{\mathrm{A}}$ & $4.52 \pm 0.05^{\mathrm{A}}$ & $4.24 \pm 0.03^{\mathrm{B}}$ & $4.23 \pm 0.02^{\mathrm{B}}$ \\
\hline FM-ST 1303 & $4.53 \pm 0.02^{\mathrm{A}}$ & $4.48 \pm 0.04^{\mathrm{A}}$ & $4.50 \pm 0.02^{\mathrm{A}}$ & $4.60 \pm 0.04^{\mathrm{A}}$ \\
\hline FM-ST $1303+0.125 \%$ PEPS & $4.64 \pm 0.04^{\mathrm{A}}$ & $4.41 \pm 0.03^{\mathrm{B}}$ & $4.40 \pm 0.04^{\mathrm{B}}$ & $4.53 \pm 0.03^{\mathrm{A}}$ \\
\hline FM-ST $1303+0.25 \%$ PEPS & $4.62 \pm 0.04^{\mathrm{A}}$ & $4.46 \pm 0.04^{\mathrm{B}}$ & $4.50 \pm 0.10^{\mathrm{AB}}$ & $4.59 \pm 0.03^{\mathrm{A}}$ \\
\hline FM-ST $1303+0.5 \%$ PEPS & $4.63 \pm 0.05^{\mathrm{AB}}$ & $4.49 \pm 0.02^{\mathrm{A}}$ & $4.62 \pm 0.06^{\mathrm{AB}}$ & $4.66 \pm 0.04^{\mathrm{B}}$ \\
\hline \multicolumn{5}{|l|}{ Titratable acidity (\%) } \\
\hline FM-ST 1275 & $0.938 \pm 0.034^{\mathrm{A}}$ & $0.968 \pm 0.045^{\mathrm{AB}}$ & $1.073 \pm 0.013^{\mathrm{BC}}$ & $1.178 \pm 0.047^{\mathrm{C}}$ \\
\hline FM-ST 1303 & $0.923 \pm 0.023^{\mathrm{A}}$ & $1.016 \pm 0.018^{\mathrm{B}}$ & $0.963 \pm 0.030^{\mathrm{AB}}$ & $0.920 \pm 0.027^{\mathrm{A}}$ \\
\hline FM-ST $1303+0.125 \%$ PEPS & $0.975 \pm 0.047^{\mathrm{A}}$ & $1.080 \pm 0.023^{\mathrm{B}}$ & $1.034 \pm 0.011^{\mathrm{AB}}$ & $0.984 \pm 0.045^{\mathrm{A}}$ \\
\hline FM-ST $1303+0.25 \%$ PEPS & $0.983 \pm 0.047^{\mathrm{A}}$ & $1.077 \pm 0.014^{\mathrm{A}}$ & $1.046 \pm 0.042^{\mathrm{A}}$ & $0.983 \pm 0.034^{\mathrm{A}}$ \\
\hline FM-ST $1303+0.5 \%$ PEPS & $0.930 \pm 0.013^{\mathrm{A}}$ & $1.080 \pm 0.054^{\mathrm{B}}$ & $1.013 \pm 0.022^{\mathrm{B}}$ & $0.911 \pm 0.011^{\mathrm{A}}$ \\
\hline
\end{tabular}



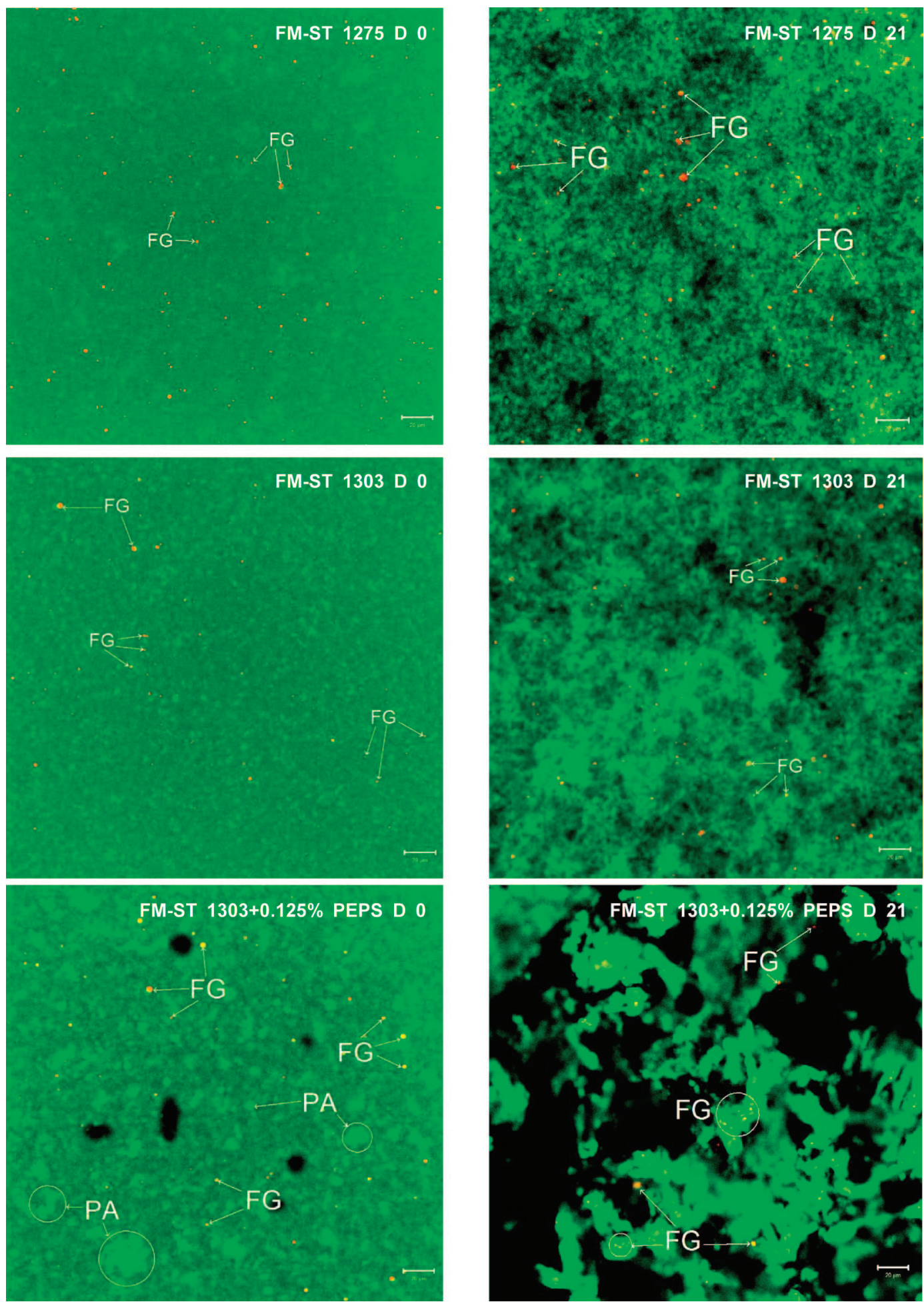

Figure 1. Confocal laser scanning light microscopy showing the structures of FM-ST 1275, FM-ST 1303, FM-ST 1303+0.125\% PEPS, FM-ST 1303+0.25\% PEPS, and FM-ST 1303+0.5\% PEPS stored for $0 \mathrm{~d}$ (D 0) and $21 \mathrm{~d}$ (D 21) at $4^{\circ} \mathrm{C}$. Scale bar corresponds to $20 \mu \mathrm{m}$. PA $=$ protein aggregate; FG = fat globule; FM-ST 1275 = milk fermented by Streptococcus thermophilus Australian Starter Culture Collection (ASCC) 1275; FM-ST 1303 = milk fermented by Strep. thermophilus ASCC 1303; PEPS = Pleurotus eryngii polysaccharides. The PEPS were added as mass percent. 

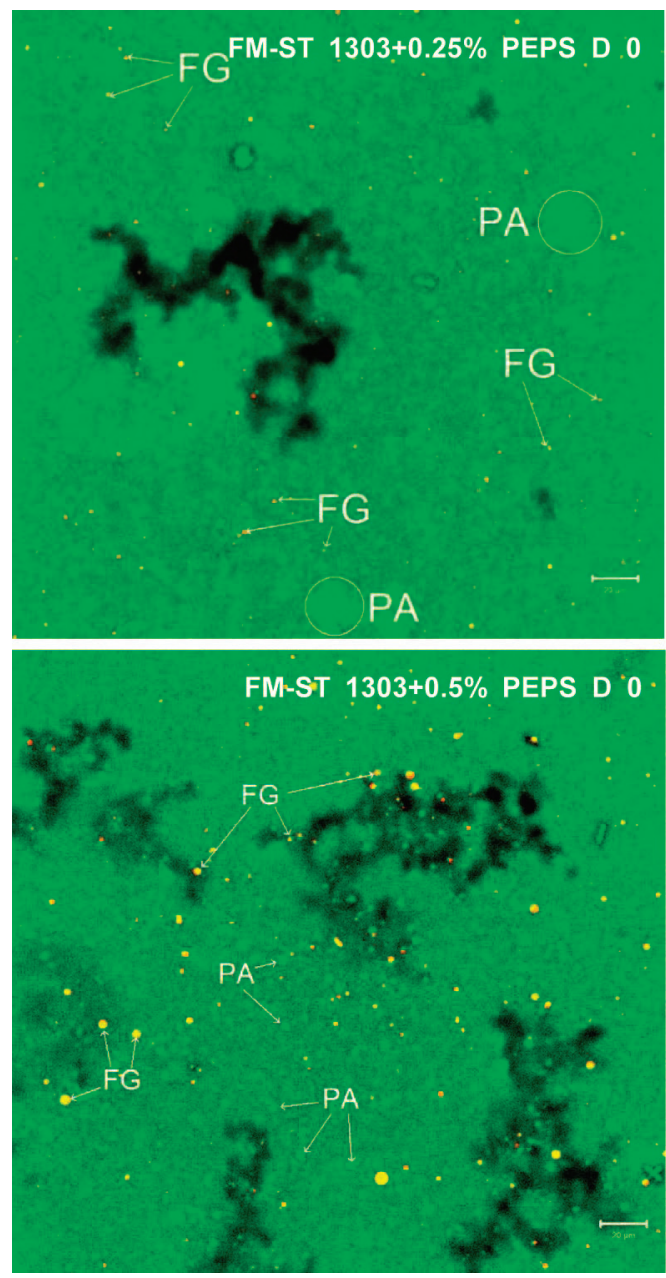
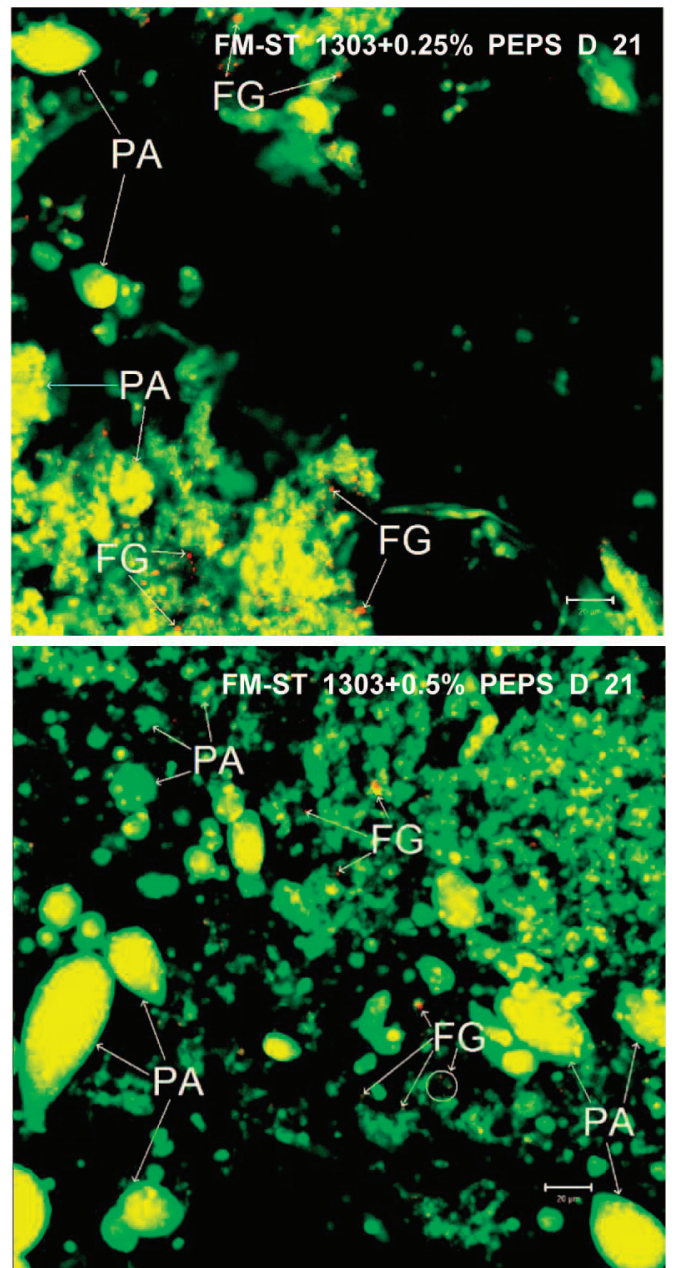

Figure 1 (Continued). Confocal laser scanning light microscopy showing the structures of FM-ST 1275, FM-ST 1303, FM-ST 1303+0.125\% PEPS, FM-ST 1303+0.25\% PEPS, and FM-ST 1303+0.5\% PEPS stored for $0 \mathrm{~d}$ (D 0) and $21 \mathrm{~d}$ (D 21) at $4^{\circ} \mathrm{C}$. Scale bar corresponds to $20 \mu \mathrm{m}$. $\mathrm{PA}=$ protein aggregate; FG = fat globule; FM-ST $1275=$ milk fermented by Streptococcus thermophilus Australian Starter Culture Collection (ASCC) 1275; FM-ST 1303 = milk fermented by Strep. thermophilus ASCC 1303; PEPS = Pleurotus eryngii polysaccharides. The PEPS were added as mass percent.

tein aggregates at $\mathrm{d} 0$ were denser and fat globules were fewer compared with those of FM-ST 1275 at d 0. Both FM-ST 1275 and FM-ST 1303 showed obvious protein aggregates containing small serum pores after $21 \mathrm{~d}$ of storage at $4^{\circ} \mathrm{C}$, and the protein aggregates of FM-ST 1303 D 21 appeared to be thicker than those of FM-ST 1275 D 21. Also, fewer fat globules were observed in FM-ST 1303 D 21 compared with those of FM-ST 1275 D 21. Micrographs showed no significant differences on fat-globule shape and size between FM-ST 1275 and FM-ST 1303 (D 0 and D 21). In Figure 1, small serum pores were observed in FM-ST $1303+0.125 \%$ PEPS D 0, FM-ST $1303+0.25 \%$ PEPS D 0, and FM-ST $1303+0.5 \%$ PEPS D 0. Additionally, FM with higher contents of PEPS added had more and larger areas of serum pores. There were also obvious formations of small serum pores and protein aggregates in FM-ST
$1303+0.125 \%$ PEPS D 0, FM-ST $1303+0.25 \%$ PEPS D 0, and FM-ST 1303+0.5\% PEPS D 0 compared with those of FM-ST 1303 D 0. Devi et al. (2013) reported that $0.6 \%$ (wt/wt) gelatin in a milk-gelatin mixture led to obvious protein aggregation and also that highly ruptured colloidal casein produced denser aggregates in milk-gelation mixtures. Similar to Devi et al. (2013), protein aggregation may have happened in our samples before fermentation because of the colloidal property of PEPS in aqueous solution. Additionally, Shah (2007) reported that the starter culture produced proteolytic enzymes that hydrolyzed proteins in milk and converted lactose into lactic acid in yogurt; this stimulated the aggregation of protein (casein micelles) into a gel structure. This could be another reason for larger aggregation in FM samples with added PEPS. Furthermore, protein aggregates and small serum pores 
formed in d 0 could accelerate later protein aggregation of FM-ST $1303+0.125 \%$ PEPS, FM-ST $1303+0.25 \%$ PEPS, and FM-ST 1303+0.5\% PEPS during refrigerated storage. Accordingly, micrographs showed dense large-protein aggregates containing large serum pores in FM-ST 1303+0.125\% PEPS D 21, FM-ST 1303+0.25\% PEPS D 21, and FM-ST $1303+0.5 \%$ PEPS D 21. The network of FM-ST $1303+0.125 \%$ PEPS D 21 was less dense and more homogeneous as compared with those of $1303+0.25 \%$ PEPS D 21 and FM-ST $1303+0.5 \%$ PEPS D 21. In contrast, large and concentrated protein aggregates were observed in FM-ST 1303+0.5\% PEPS D 21, and its structure was more heterogeneous and contained a large area of serum. Guggisberg et al. (2009) reported that additional inulin stimulated the protein aggregation in set yogurt, and the stimulation effects increased with increasing inulin concentrations, which were similar with the results in our study.

\section{SWS}

Spontaneous whey separation is defined as the appearance of whey on the gel surface of yogurts, which is a major defect in yogurt or frozen yogurt (Lucey, 2001). The changes in the SWS values of FM during refrigerated storage are presented in Figure 2. For FM, except those of FM-ST $1303+0.125 \%$ PEPS, the SWS values decreased at $\mathrm{d} 7$ as compared with those of $\mathrm{d} 0$ and kept increasing at d 14 and 21. For inulin-containing probiotic yogurt, Ramchandran and Shah (2010b) reported that the SWS values of yogurt without EPS and yogurt with EPS decreased at d 1, 7, and 14 and then increased at d 21 and 28 during refrigerated storage; these trends were similar to our study. For FM-ST 1275 and FM-ST 1303, the SWS values of FM-ST 1303 were higher than those of FM-ST 1275 at d 7, 14, and 21, which agrees with the results reported by Ramchandran and Shah (2010b) and Amatayakul et al. (2006). The SWS values of FM-ST $1303+0.5 \%$ PEPS, FM-ST $1303+0.25 \%$ PEPS, and FM-ST $1303+0.125 \%$ PEPS were significantly $(P<0.05)$ higher than those of FMST 1303 during refrigerated storage; these were in the order FM-ST 1303+0.5\% PEPS > FM-ST $1303+0.25 \%$ PEPS > FM-ST $1303+0.125 \%$ PEPS. Our results showed that FM prepared using EPS-producing bacteria (ST 1275) had better water-holding capacity and thereby lower SWS values, whereas additional PEPS led to significantly $(P<0.05)$ higher SWS values of yogurt compared with FM-ST 1303 and FM-ST 1275. Miao et al. (2011) observed that yogurts made with $1.5 \%$ (wt/vol) water-soluble polysaccharides from truffles had lower syneresis compared with yogurts without water-soluble polysaccharides. Folkenberg et al. (2006) reported that yogurts should have medium- size pores in the matrix to provide stable structures. The confocal micrographs (Figure 1) showed that serum pores in FM-ST 1303 D 21 were larger and the protein aggregates were denser compared with those of FM-ST 1275 D 21, which may be the main reason for higher SWS values of FM-ST 1303 at d 7, 14, and 21 during refrigerated storage. Fiszman et al. (1999) reported that syneresis could be increased by reducing the casein content of the milk before fermentation. The colloidal property of PEPS may lead to the protein aggregation in milk, which resulted in the decrease of casein in milk before fermentation in our study (Devi et al., 2013). Accordingly, the SWS values of FM-ST $1303+0.125 \%$ PEPS, FM-ST $1303+0.25 \%$ PEPS, and FM-ST $1303+0.5 \%$ PEPS were higher compared with that of FM-ST 1303 during refrigerated storage. Additionally, confocal micrographs also showed that FM-ST $1303+0.125 \%$ PEPS, FM-ST 1303+0.25\% PEPS, and FM-ST $1303+0.5 \%$ PEPS had larger areas of serum, which was consistent with higher SWS values for those samples. In our study, additional PEPS may have led to larger size pores formed inside the FM matrix, leading to shrinkage of the FM matrix, which resulted in higher SWS values for those FM samples during fermentation.

\section{Extent of Proteolysis}

The growth of bacteria in the yogurts and acidification of yogurts are related to the proteolytic capabilities of bacteria in yogurts (Ramchandran and Shah, 2010a). The changes in proteolytic capabilities of FM during refrigerated storage are presented in Figure 3. The proteolytic capabilities of all FM samples increased during refrigerated storage, and the capabilities of samples with additional PEPS were in the order FMST $1303+0.5 \%$ PEPS > FM-ST $1303+0.25 \%$ PEPS > FM-ST $1303+0.125 \%$ PEPS at d 7, 14, and 21. Proteolytic capabilities of all FM samples did not significantly differ at $\mathrm{d} 7$ and 14, although there was a slight increase from d 7 to 14 . The proteolytic capabilities of FM-ST $1303+0.5 \%$ PEPS, FM-ST $1303+0.25 \%$ PEPS, and FM-ST $1303+0.125 \%$ PEPS increased significantly $(P$ $<0.05)$ at $d 21$ compared with those at d 14. The proteolytic capability of FM-ST $1303+0.5 \%$ PEPS at d $21(1.647 \pm 0.053)$ increased by $60.84 \%$ as compared with that of $\mathrm{d} 14(1.024 \pm 0.029)$, and that of FM-ST $1303+0.25 \%$ PEPS and FM-ST $1303+0.125 \%$ PEPS increased 29.15 and $18.30 \%$ from d 14 to 21 individually. The proteolytic capabilities of FM-ST 1275 were significantly $(P<0.05)$ higher than those of FM-ST 1303 during refrigerated storage, which was consistent with the results reported by Guzel-Seydim et al. (2005). Proteinase and peptidases in lactic acid bacteria are responsible for proteolysis of caseins (Shihata and Shah, 


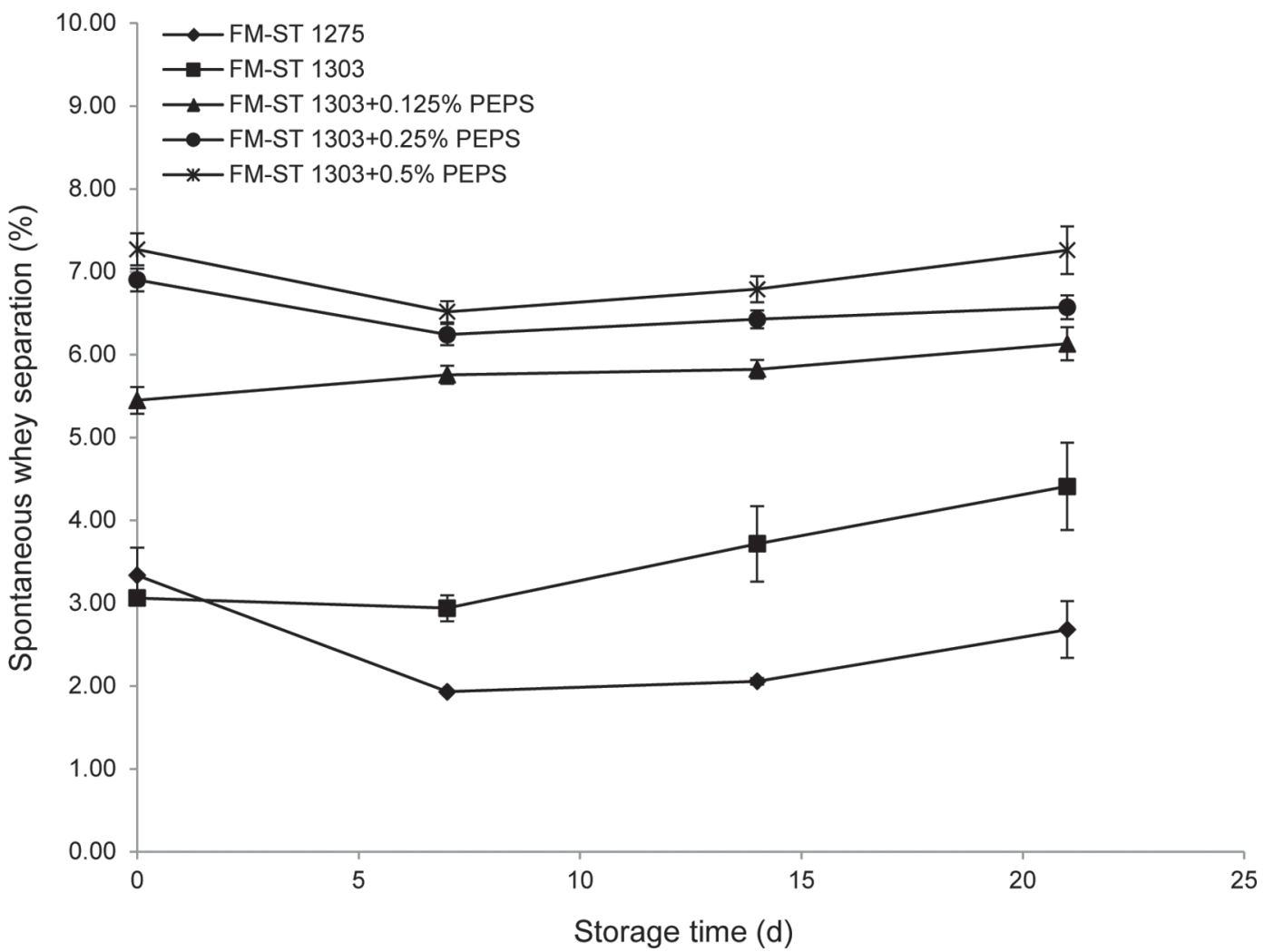

Figure 2. Changes in spontaneous whey separation (\%) of fermented-milk samples during $21 \mathrm{~d}$ of storage at $4^{\circ} \mathrm{C}$. Values are expressed as mean $\pm \mathrm{SD}, \mathrm{n}=3$. FM-ST $1275=$ milk fermented by Streptococcus thermophilus Australian Starter Culture Collection (ASCC) 1275 ; FM-ST 1303 = milk fermented by Strep. thermophilus ASCC 1303; PEPS = Pleurotus eryngii polysaccharides. The PEPS were added as mass percent.

2000). The continued proteolysis could have provided the essential growth factors in the form of peptides and amino acids to improve the survival of the bacteria in FM (Table 1). The proteolytic capabilities increased during refrigerated storage because the bacteria were unable to use all peptides and amino acids that were liberated from casein. Our results showed that additional PEPS could significantly $(P<0.05)$ improve the proteolytic capabilities of ST 1303.

\section{Determination of ACE-Inhibitory Activity}

Angiotensin-I-converting enzyme-inhibitory peptides are defined as those bioactive peptides that have demonstrated antihypertensive properties. Those peptides are produced as metabolites of bacterial proteinases and peptidases that have been widely found in dairy products (Gandhi and Shah, 2014). The changes in ACE-inhibitory activities and corresponding $\mathrm{EC}_{50}$ values of FM during refrigerated storage are presented in Table 3. The ACE-inhibitory activity of FM-ST 1275 significantly $(P<0.05)$ increased at d $7(29.81 \pm$ $2.45 \%)$ as compared with that of $\mathrm{d} 0(12.55 \pm 0.90 \%)$.
Then its ACE-inhibitory activities significantly $(P<$ $0.05)$ decreased at $\mathrm{d} 14(20.83 \pm 1.43 \%)$ and $\mathrm{d} 21$ (15.04 $\pm 1.93 \%)$. For FM-ST 1303, FM-ST 1303+0.5\% PEPS, FM-ST 1303+0.25\% PEPS, and FM-ST 1303+0.125\% PEPS, the ACE-inhibitory activities were maximum at d 14 and then decreased at d 21. The ACE-inhibitory activities of FM-ST 1275 were the lowest compared with those of other FM samples at the same storage period. Additionally, the ACE-inhibitory activities of FM with added PEPS were in the order FM-ST $1303+0.125 \%$ PEPS > FM-ST $1303+0.25 \%$ PEPS > FM-ST $1303+0.5 \%$ PEPS at $\mathrm{d} 0,7$, and 14 , which showed that higher percentage of PEPS in FM may lead to lower ACE-inhibitory activity. Ramchandran and Shah (2010b) reported similar results that ACEinhibitory activities of yogurt without EPS and yogurt with EPS sharply increased at $\mathrm{d} 7$ and then decreased at $\mathrm{d} 14$ and 21 during refrigerated storage. The $\mathrm{EC}_{50}$ values kept increasing during refrigerated storage for FM-ST $1303+0.5 \%$ PEPS (1.234 to $5.842 \mathrm{mg} / \mathrm{mL}$ ), FM-ST $1303+0.25 \%$ PEPS (0.670 to $5.336 \mathrm{mg} / \mathrm{mL}$ ), and FM-ST $1303+0.125 \%$ PEPS (0.912 to $3.584 \mathrm{mg} /$ $\mathrm{mL}$ ) because of the increase in the amino acid contents 


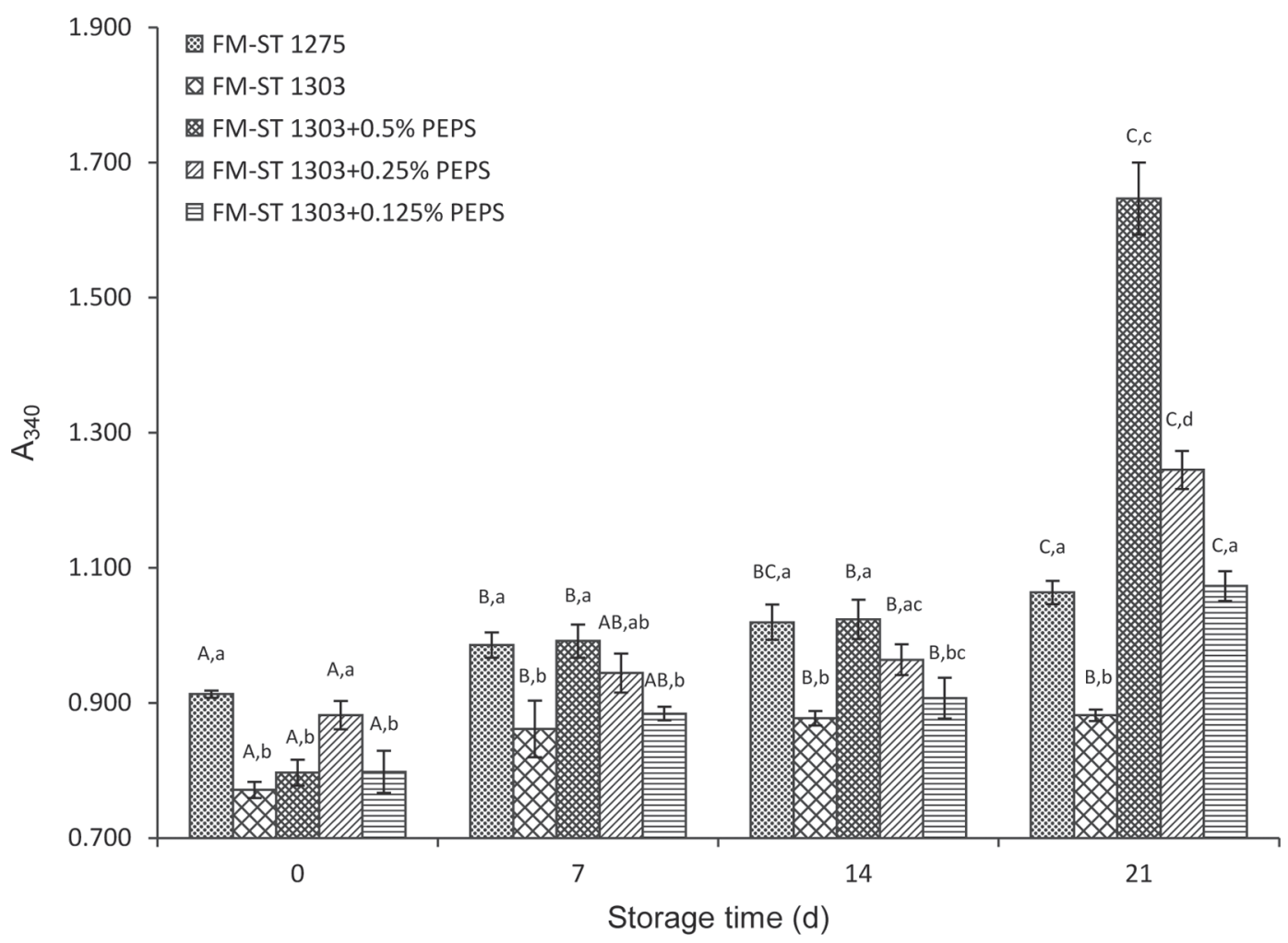

Figure 3. Changes in proteolytic capability (absorbance at $340 \mathrm{~nm} ; \mathrm{A}_{340}$ ) of fermented-milk samples during $21 \mathrm{~d}$ of storage at $4^{\circ} \mathrm{C}$. Values are expressed as mean $\pm \mathrm{SD}, \mathrm{n}=3 .{ }^{\mathrm{A}-\mathrm{C}}$ Means for the same sample of different storage days without common letters are significantly different $(P<0.05)$. ${ }^{\mathrm{a}-\mathrm{d}}$ Means for the same storage day of different samples without common letters are significantly different $(P<0.05)$. FM-ST 1275 $=$ milk fermented by Streptococcus thermophilus Australian Starter Culture Collection (ASCC) 1275; FM-ST $1303=$ milk fermented by Strep . thermophilus ASCC 1303; PEPS = Pleurotus eryngii polysaccharides. The PEPS were added as mass percent.

determined in our study. The continual proteolytic capacity in FM could modify the concentration of the peptides possessing ACE-inhibitory activities, which could have contributed to the variations in the ACEinhibitory activities during refrigerated storage. The $\mathrm{EC}_{50}$ values showed that higher amounts of peptides or amino acids in FM may not exert higher ACE-inhibitory activity. Salami et al. (2011) and Vermeirssen et al. (2003) reported that amino acid compositions and also the size and sequence of those amino acids were found to play key roles in inhibition of ACE activities but not the quantity of peptides.

\section{Texture Analysis}

Firmness and gumminess are common parameters to evaluate the texture of FM products. The changes in firmness and gumminess of FM during refrigerated storage are presented in Table 4 . Both firmness and gumminess of FM-ST 1275 were higher than those of FM-ST 1303 at $\mathrm{d} 7,14$, and 21 . The firmness kept increasing for all FM samples during refrigerated storage. Prasad et al. (2013) also observed the increasing firmness trend during refrigerated storage of the nonfat yogurts with galactooligosaccharides or modified waxy maize starch added as prebiotics. The firmness and gumminess of FM with additional PEPS were higher than those of FM-ST 1303 and FM-ST 1275. Among FM-ST 1275, FM-ST 1303, and FM-ST 1303+0.125\% PEPS, gumminess did not significantly differ. The gumminess of FM-ST $1303+0.25 \%$ PEPS at d $0(72.872 \pm 2.142)$ and d $7(86.186 \pm 1.093)$ were lower than those of FM-ST $1303+0.5 \%$ PEPS $(95.694 \pm 1.322$, d 0; $86.918 \pm 4.094$, d 7), whereas the gumminess of FM-ST 1303+0.25\% PEPS $(99.691 \pm 1.464, \mathrm{~d} 14 ; 107.518 \pm 3.810, \mathrm{~d} 21)$ were higher than those of FM-ST 1303+0.5\% PEPS $(89.728 \pm 1.209, \mathrm{~d} 14 ; 85.379 \pm 1.152, \mathrm{~d} 21)$ at d 14 and 21. Hassan (2008) reported that high-molecular-mass EPS has the ability to strengthen the firmness of the network by interacting with other milk constituents. Our results showed that FM with added PEPS had higher syneresis and also higher firmness and gumminess compared with those of FM-ST 1275 and FM-ST 1303, which may be caused by the high-molecular-mass PEPS added in FM. 
Table 3. Changes in angiotensin-I-converting enzyme (ACE)-inhibitory activity (\%) and corresponding $\mathrm{EC}_{50}$ [the protein concentration in the sample $(\mathrm{mg} / \mathrm{mL})$ effective to inhibit $50 \%$ of the ACE activity] values of fermented-milk samples during $21 \mathrm{~d}$ of storage at $4^{\circ} \mathrm{C}^{1}$

\begin{tabular}{|c|c|c|c|c|}
\hline \multirow[b]{2}{*}{ Sample $^{2}$} & \multicolumn{4}{|c|}{ Period of storage (d) } \\
\hline & 0 & 7 & 14 & 21 \\
\hline \multicolumn{5}{|l|}{ ACE inhibitory (\%) } \\
\hline FM-ST 1275 & $12.55 \pm 0.90^{\mathrm{A}, \mathrm{a}}$ & $29.81 \pm 2.45^{\mathrm{B}, \mathrm{a}}$ & $20.83 \pm 1.43^{\mathrm{AB}, \mathrm{a}}$ & $15.04 \pm 1.93^{\mathrm{AB}, \mathrm{a}}$ \\
\hline FM-ST 1303 & $35.29 \pm 2.12^{\mathrm{A}, \mathrm{b}}$ & $44.17 \pm 3.10^{\mathrm{AB}, \mathrm{a}}$ & $56.06 \pm 2.92^{\mathrm{B}, \mathrm{b}}$ & $39.23 \pm 0.92^{\mathrm{AB}, \mathrm{b}}$ \\
\hline FM-ST $1303+0.125 \%$ PEPS & $35.69 \pm 2.07^{\mathrm{A}, \mathrm{b}}$ & $49.05 \pm 2.38^{\mathrm{A}, \mathrm{b}}$ & $52.65 \pm 3.47^{\mathrm{A}, \mathrm{bc}}$ & $38.94 \pm 3.34^{\mathrm{A}, \mathrm{b}}$ \\
\hline FM-ST $1303+0.25 \%$ PEPS & $31.76 \pm 1.18^{\mathrm{A}, \mathrm{b}}$ & $38.48 \pm 1.54^{\mathrm{A}, \mathrm{a}}$ & $38.64 \pm 1.14^{\mathrm{A}, \mathrm{bc}}$ & $32.74 \pm 2.69^{\mathrm{A}, \mathrm{b}}$ \\
\hline FM-ST $1303+0.5 \%$ PEPS & $27.45 \pm 2.07^{\mathrm{A}, \mathrm{b}}$ & $31.71 \pm 2.67^{\mathrm{A}, \mathrm{a}}$ & $35.61 \pm 1.83^{\mathrm{A}, \mathrm{c}}$ & $33.63 \pm 0.44^{\mathrm{A}, \mathrm{b}}$ \\
\hline \multicolumn{5}{|l|}{$\mathrm{EC}_{50}(\mathrm{mg} / \mathrm{mL})$} \\
\hline FM-ST 1275 & 3.041 & 0.814 & 1.085 & 1.936 \\
\hline FM-ST 1303 & 0.991 & 0.971 & 0.789 & 1.906 \\
\hline FM-ST $1303+0.125 \%$ PEPS & 0.912 & 0.920 & 1.060 & 3.584 \\
\hline FM-ST 1303+0.25\% PEPS & 0.670 & 1.373 & 2.215 & 5.336 \\
\hline FM-ST $1303+0.5 \%$ PEPS & 1.234 & 2.355 & 3.429 & 5.842 \\
\hline
\end{tabular}

The shelf-life of natural yogurt without heat treatment or pasteurization is 4 to $5 \mathrm{wk}$ at $4^{\circ} \mathrm{C}$. Residual activities of bacteria in natural yogurts lead to increase in titratable acidity, which is referred as postacidification in industry (Shah, 2003). Our study indicated that the shelf-life of FM with additional PEPS is 1 to 2 wk as the viabilities of ST 1275 or ST 1303 were significantly decreased $(P<0.05)$ and the proteolysis, firmness, and gumminess were significantly increased $(P<0.05)$ at $\mathrm{d}$ 21 compared with those at d 0,7 , and 14 during storage at $4^{\circ} \mathrm{C}$. Additionally, confocal micrographs showed denser protein aggregates and large serum pores at d 21, which also indicated that the qualities of FM samples with additional PEPS were optimal within 14 d during storage at $4^{\circ} \mathrm{C}$.

\section{CONCLUSIONS}

Additional PEPS had considerable effects on bacterial growth, texture properties, and proteolytic and ACEinhibitory activities of FM during refrigerated storage. Viable counts of FM-ST 1275+0.5\% PEPS were high-

Table 4. Changes in firmness and gumminess of fermented-milk samples during $21 \mathrm{~d}$ of storage at $4^{\circ} \mathrm{C}^{1}$

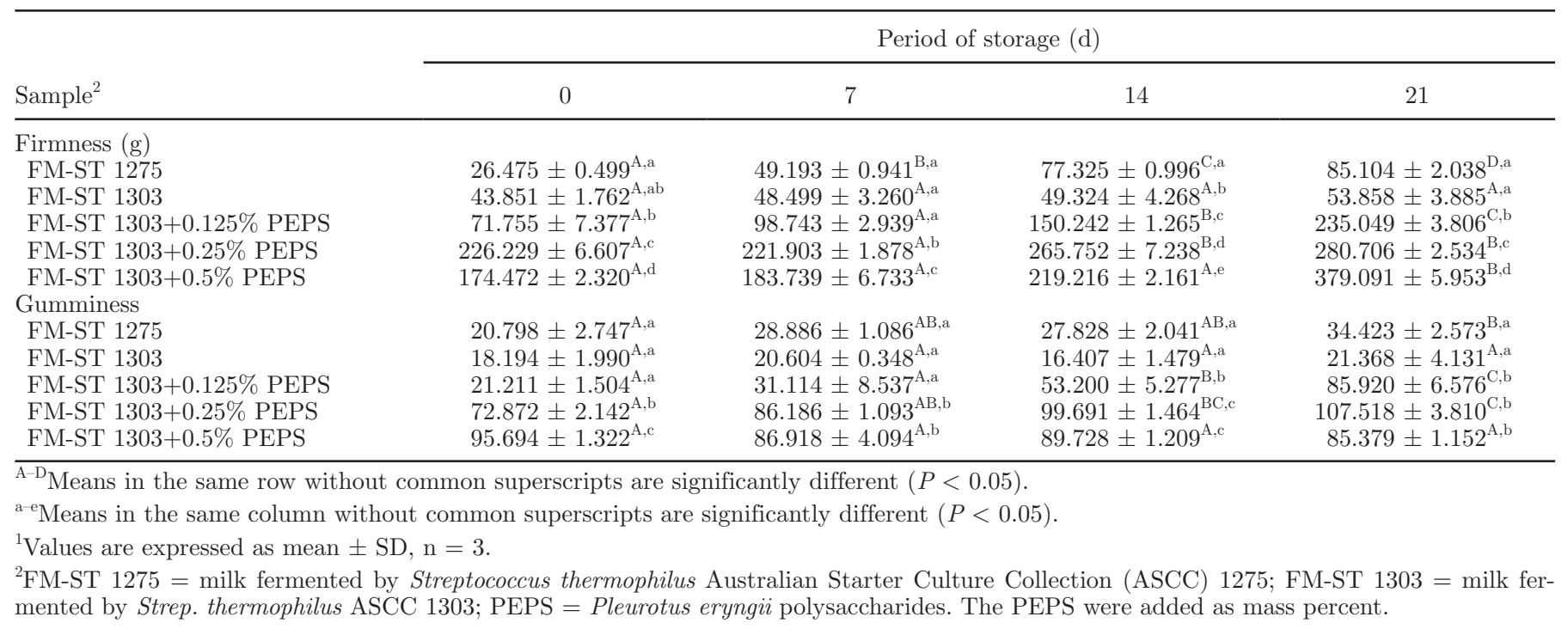


est and decreased slowest, which indicated that PEPS could provide a growth factor to maintain the growth of ST 1275 during refrigerated storage. For FM-ST 1275 , $\mathrm{pH}$ decreased during refrigerated storage, whereas for other FM samples, $\mathrm{pH}$ decreased at $\mathrm{d} 7$ and slightly increased at d 14 and 21. Confocal micrographs showed denser protein aggregates and larger serum pores in FM-ST $1303+0.125 \%$ PEPS, FM-ST $1303+0.25 \%$ PEPS, and FM-ST 1303+0.5\% PEPS compared with those of FM-ST 1303 and FM-ST 1275 at d 0 and 21 during refrigerated storage. The SWS values of FM with added PEPS were significantly higher than those of FM-ST 1275 and FM-ST 1303, of which FM-ST 1275 had the lowest SWS values during refrigerated storage. The proteolytic capabilities of FM with added PEPS were higher than those of FM-ST 1303, and the FM-ST $1303+0.5 \%$ PEPS had similar proteolytic capability to FM-ST 1275 at d 7 and 14, then its proteolytic capability sharply increased and was significantly higher than that of FM-ST 1275 at d 21. The FM-ST 1303+0.125\% PEPS had similar ACE-inhibitory activity with that of FM-ST 1303, and both of them were higher than those of other FM samples during refrigerated storage. For FM with added PEPS, both firmness and gumminess values were higher than those of FM-ST 1303 and FM-ST 1275, and FM-ST 1303 had the lowest firmness and gumminess values during refrigerated storage. Our study indicated that Pleurotus eryngii polysaccharides may be considered as a nutritional additive for adding to milk before fermentation to improve health benefits of FM products.

\section{REFERENCES}

Amatayakul, T., A. L. Halmos, F. Sherkat, and N. P. Shah. 2006 Physical characteristics of yogurts made using exopolysaccharideproducing starter cultures and varying casein to whey protein ratios. Int. Dairy J. 16:40-51.

AOAC International. 1999. Official Methods of Analysis. Vol. II. 5th rev. AOAC Int., Rockville, MD.

Bobek, P., and S. Galbavy. 2001. Effect of pleuran ( $\beta$-glucan from Pleurotus ostreatus) on the antioxidant status of the organism and on dimethylhydrazine-induced precancerous lesions in rat colon. Br. J. Biomed. Sci. 58:164-168.

Chen, J., D. Mao, Y. Yong, J. Li, H. Wei, and L. Lu. 2012. Hepatoprotective and hypolipidemic effects of water-soluble polysaccharidic extract of Pleurotus eryngii. Food Chem. 130:687-694.

Church, F. C., H. E. Swaisgood, D. H. Porter, and G. L. Catignani. 1983. Spectrophotometric assay using o-phthaldialdehyde for determination of proteolysis in milk and isolated milk proteins. J. Dairy Sci. 66:1219-1227.

Cruz, N. S., M. Capellas, D. P. Jaramillo, A. J. Trujillo, B. Guamis, and V. Ferragut. 2009. Soymilk treated by ultra high-pressure homogenization: Acid coagulation properties and characteristics of a soy-yogurt product. Food Hydrocoll. 23:490-496.

Cushman, D. W., and H. S. Cheung. 1971. Spectrophotometric assay and properties of the angiotensin-converting enzyme of rabbit lung. Biochem. Pharmacol. 20:1637-1648.
Devi, A. F., L. H. Liu, Y. Hemar, R. Buckow, and S. Kasapis. 2013 Effect of high pressure processing on rheological and structural properties of milk-gelatin mixtures. Food Chem. 141:1328-1334.

Dubois, M. K. A. Gilles, J. K. Hamilton, P. A. Rebers, and F. Smith 1956. Colorimetric method for determination of sugars and related substances. Anal. Chem. 28:350-356.

Ferreira, I. C. F. R., L. Barros, and R. M. V. Abreu. 2009. Antioxidants in wild mushrooms. Curr. Med. Chem. 16:1543-1560.

Fiszman, S. M., M. A. Lluch, and A. Salvador. 1999. Effect of addition of gelatin on microstructure of acidic milk gels and yoghurt and on their rheological properties. Int. Dairy J. 9:895-901.

Folkenberg, D. M., P. Dejmek, A. Skriver, and R. Ipsen. 2006. Interactions between EPS-producing Streptococcus thermophilus strains in mixed yogurt cultures. J. Dairy Res. 73:385-393.

Gandhi, A., and N. P. Shah. 2014. Effects of salt concentration and $\mathrm{pH}$ on structural and functional properties of Lactobacillus acidophilus: FT-IR spectroscopic analysis. Int. J. Food Microbiol. 173:41-47.

Guggisberg, D., J. Cuthbert-Steven, P. Piccinali, U. Bütikofer, and P. Eberhard. 2009. Rheological, microstructural and sensory characterization of low-fat and whole milk set yogurt as influenced by inulin addition. Int. Dairy J. 19:107-115.

Guzel-Seydim, Z. B., E. Sezgin, and A. C. Seydim. 2005. Influences of exopolysaccharide producing cultures on the quality of plain set type yogurt. Food Contr. 16:205-209.

Hassan, A. N. 2008. ADSA Foundation Scholar Award: Possibilities and challenges of exopolysaccharide-producing lactic cultures in dairy foods. J. Dairy Sci. 91:1282-1298.

Hassan, A. N., J. F. Frank, and K. A. Schmidt. 1996. Textural properties of yogurt made with encapsulated nonropy lactic cultures. J. Dairy Sci. 79:2098-2103.

Li, S., and N. P. Shah. 2014. Antioxidant and antibacterial activities of sulfated polysaccharides from Pleurotus eryngii and Streptococcus thermophilus ASCC 1275. Food Chem. 165:262-270.

Lowry, O. H., N. J. Rosebrough, A. L. Farr, and R. J. Randall. 1951 Protein measurement with the Folin-phenol reagent. J. Biol. Chem. 193:265-275.

Lucey, J. A. 2001. The relationship between rheological parameters and whey separation in milk gels. Food Hydrocoll. 15:603-608.

Miao, Y. Z., Q. Lin, Y. Cao, G. H. He, D. R. Qiao, and Y. Cao. 2011 Extraction of water-soluble polysaccharides (WSPS) from Chinese truffle and its application in frozen yogurt. Carbohydr. Polym. 86:566-573.

Miller, G. L. 1959. Use of dinitrosalicylic acid reagent for determination of reducing sugar. Anal. Chem. 31:426-428.

Nguyen, H. T. H., L. Ong, C. Lefèvre, S. E. Kentish, and S. L. Gras. 2014. The microstructure and physicochemical properties of probiotic buffalo yoghurt during fermentation and storage: A comparison with bovine yoghurt. Food Bioprocess Technol. 7:937-953.

Ping, C. X., C. Yan, L. S. Bing, C. Y. Guo, L. J. Yun, and L. L. Ping. 2009. Free radical scavenging of Ganoderma lucidum polysaccharides and its effect on antioxidant enzymes and immunity activities in cervical carcinoma rats. Carbohydr. Polym. 77:389-393.

Prasad, L. N., F. Sherkat, and N. P. Shah. 2013. Influence of galactooligosaccharides and modified waxy maize starch on some attributes of yogurt. J. Food Sci. 78:M77-M83.

Purwandari, U., N. P. Shah, and T. Vasiljevic. 2007. Effects of exopolysaccharide-producing strains of Streptococcus thermophilus on technological and rheological properties of set-type yoghurt. Int. Dairy J. 17:1344-1352.

Ramchandran, L., and N. P. Shah. 2009. Effect of exopolysaccharides and inulin on the proteolytic, angiotensin-I-converting enzymeand $\alpha$-glucosidase-inhibitory activities as well as on textural and rheological properties of low-fat yogurt during refrigerated storage. Dairy Sci. Technol. 89:583-600.

Ramchandran, L., and N. P. Shah. 2010a. Influence of addition of Raftiline $\mathrm{HP}^{\circledast}$ on the growth, proteolytic, ACE- and $\alpha$-glucosidase inhibitory activities of selected lactic acid bacteria and Bifidobacterium. LWT Food Sci. Technol. (Campinas.) 43:146-152. 
Ramchandran, L., and N. P. Shah. 2010b. Characterization of functional, biochemical and textural properties of synbiotic low-fat yogurts during refrigerated storage. LWT Food Sci. Technol. (Campinas.) 43:819-827.

Salami, M., A. A. Moosavi-Movahedi, F. Moosavi-Movahedi, M. R. Ehsani, R. Yousefi, M. Farhadi, A. Niasari-Naslaji, A. A. Saboury, J.-M. Chobert, and T. Haertlé. 2011. Biological activity of camel milk casein following enzymatic digestion. J. Dairy Res. 78:471-478.

Shah, N. P. 2003. Yogurt: The product and its manufacture. Pages 6252-6260 in Encyclopedia of Food Sciences and Nutrition. 2nd ed. L. Trugo, P. Finglas, and B. Caballero, ed. Acad. Press, London, UK.

Shah, N. P. 2007. Functional cultures and health benefits. Int. Dairy J. $17: 1262-1277$.

Shihata, A., and N. P. Shah. 2000. Proteolytic profiles of yogurt and probiotic bacteria. Int. Dairy J. 10:401-408.

Tinson, W., M. C. Broome, A. J. Hillier, and G. R. Jago. 1982. Metabolism of Streptococcus thermophilus. 2. Production of $\mathrm{CO}_{2}$ and $\mathrm{NH}_{3}$ from urea. Aust. J. Dairy Technol. 37:14-16. van den Berg, L., T. van Vliet, E. van der Linden, M. A. J. S. van Boekel, and F. van de Velde. 2007. Breakdown properties and sensory perception of whey proteins/polysaccharide mixed gels as a function of microstructure. Food Hydrocoll. 21:961-976.

Vermeirssen, V., J. Van Camp, L. Devos, and W. Verstraete. 2003. Release of angiotensin-I converting enzyme (ACE) inhibitory activity during in vitro gastrointestinal digestion: From batch experiment to semicontinuous model. J. Agric. Food Chem. 51:5680-5687.

Yang, T., K. Wu, F. Wang, X. Liang, Q. Liu, G. Li, and Q. Li. 2014. Effect of exopolysaccharides from lactic acid bacteria on the texture and microstructure of buffalo yogurt. Int. Dairy J. 34:252-256.

Zisu, B., and N. P. Shah. 2003. Effects of pH, temperature, supplementation with whey protein concentrate, and adjunct cultures on the production of exopolysaccharides by Streptococcus thermophilus 1275. J. Dairy Sci. 86:3405-3415. 